\title{
Rapid Response of Biologic Treatments of Moderate- to-Severe Plaque Psoriasis: A Comprehensive Investigation Using Bayesian and Frequentist Network Meta-analyses
}

\author{
Richard B. Warren · Kyoungah See · Russel Burge · Ying Zhang • \\ Alan Brnabic · Gaia Gallo · Alyssa Garrelts · Alexander Egeberg
}

Received: September 15, 2019

(C) The Author(s) 2019, corrected publication 2020

\section{ABSTRACT}

Introduction: Rapid improvement of psoriasis is valued by patients and should be considered to be an important factor in treatment selection. We investigated Psoriasis Area and Severity Index (PASI) and Dermatology Life Quality Index (DLQI) response rates within the first 12 weeks of treatment to compare the rapid response of 11 biologic therapies for moderate-

Enhanced Digital Features To view enhanced digital features for this article go to https://doi.org/10.6084/ m9.figshare.9994610.

Electronic supplementary material The online version of this article (https://doi.org/10.1007/s13555019-00337-y) contains supplementary material, which is available to authorized users.

\section{R. B. Warren}

Dermatology Centre, Salford Royal NHS Foundation

Trust, University of Manchester, Manchester, UK

K. See $\cdot$ R. Burge $(\bowtie) \cdot$ Y. Zhang · A. Brnabic .

G. Gallo · A. Garrelts

Eli Lilly and Company, Lilly Corporate Center, Indianapolis, IN, USA

e-mail: burge_russel_thomas@lilly.com

R. Burge

College of Pharmacy, University of Cincinnati, Cincinnati, $\mathrm{OH}, \mathrm{USA}$

\section{A. Egeberg}

Department of Dermatology and Allergy, Herlev and Gentofte Hospital, University of Copenhagen,

Copenhagen, Denmark to-severe psoriasis using Bayesian and Frequentist network meta-analyses (NMA).

Methods: A systematic literature review was conducted to identify phase 3 , double-blind, randomized, controlled trials for adult patients with moderate-to-severe psoriasis treated with interleukin (IL)-17 (brodalumab, ixekizumab, secukinumab), IL-12/-23 (ustekinumab), IL-23 (guselkumab, risankizumab, tildrakizumab), or tumor necrosis factor inhibitors (adalimumab, certolizumab pegol, etanercept, infliximab). Outcome measures extracted from 32 publications were $\geq 75, \geq 90$, or $100 \%$ improvement in PASI score (PASI 75, PASI 90, or PASI 100, respectively) at weeks $2,4,8$, and 12 and DLQI $(0,1)$, where score $(0,1)$ indicates no effect on patient's life, at week 12. Bayesian NMA (BNMA) used fixed-treatment effect and random-baseline effect, normal independent models. Frequentist NMA (fNMA) was conducted as sensitivity analyses to test the robustness of the findings.

Results: Based on BNMA and fNMA, brodalumab and ixekizumab showed the most rapid treatment effects on PASI 75 at weeks 2, 4, and 8 and on PASI 90 and PASI 100 at weeks 2, 4, 8, and 12; ixekizumab overlapped with risankizumab on PASI 75 at week 12. Brodalumab, ixekizumab, and secukinumab yielded higher DLQI $(0,1)$ gains at week 12 compared to all of the other biologics studied. Additional measures of quality of life were not assessed in this report.

Conclusions: Ixekizumab and brodalumab provide the most rapid response and earliest 
clinical benefit at week 2 among all of the biologics studied, including other biologic treatments such as secukinumab, ustekinumab, guselkumab, adalimumab, and etanercept. BNMA and fNMA results showed similar relative effect estimates and treatment rankings.

Funding: Eli Lilly and Company.

Keywords: Biologics; Meta-analysis; Psoriasis

\section{Key Summary Points}

Why carry out this study?

Multiple biologic drugs are approved for the treatment of moderate-to-severe plaque psoriasis based on efficacy and safety established in phase 3, doubleblind, randomized, controlled trials, but direct comparisons of response rates in head-to-head trials are rare, and indirect comparisons using network meta-analyses are limited

What was learned from the study?

This comprehensive network metaanalysis (NMA) examined a large number of biologics for the treatment of moderateto-severe psoriasis (adalimumab, brodalumab, certolizumab pegol, etanercept, guselkumab, infliximab, ixekizumab, risankizumab, secukinumab, tildrakizumab, ustekinumab) and focused on higher clinical response rates than previously published NMA investigations

We focused specifically on rapid response rates within 12 weeks of treatment because rapid skin clearance and quality of life improvement are important patient preferences in biologic treatment

\section{DIGITAL FEATURES}

This article is published with digital features, including a summary slide and video abstract, to facilitate understanding of the article. To view digital featuresfor this article go to https:// doi.org/10.6084/m9.figshare.9994610.

\section{INTRODUCTION}

Plaque psoriasis is a chronic, inflammatory skin disease with an estimated prevalence of $1.5-5 \%$ in the general population $[1,2]$. Psoriasis significantly impairs patients' quality of life $[1,2]$, underscoring the need for timely and effective treatments.

Biologic therapies have transformed the treatment of moderate-to-severe psoriasis and have markedly improved multiple patient outcomes [3, 4]. Several biologics are available, including inhibitors of interleukin (IL)-17 (brodalumab, ixekizumab, secukinumab), IL-12/-23 (ustekinumab), IL-23 (guselkumab, risankizumab, tildrakizumab), or tumor necrosis factor (adalimumab, certolizumab pegol, etanercept, infliximab) $[5,6]$. These biologics are approved for patients with moderate-to-severe plaque psoriasis based on efficacy and safety established in phase 3, double-blind, randomized, controlled trials (RCTs).

Rapid efficacy is important to patients and clinicians [4, 7-10], but head-to-head comparisons of biologics are rare, and none conducted to date have had speed of onset as a primary objective. We present a comprehensive network metaanalysis (NMA) that indirectly compares rapid response rates at early time points $(\leq 12$ weeks of treatment) for 11 approved biologics for moderate-to-severe psoriasis. Bayesian and Frequentist NMA (BNMA and fNMA, respectively) were used to investigate Psoriasis Area and Severity Index (PASI) and Dermatology Life Quality Index (DLQI) response from phase 3 RCTs identified by systematic literature review.

\section{METHODS}

Inclusion criteria for the studies with available data to include in the NMA have previously been reported and are listed in Electronic Supplementary Material (ESM) Table 1 . These studies included patients who were $\geq 18$ years of age with moderate-to-severe psoriasis.

This article is based on previously conducted studies and does not contain any studies with human participants or animals performed by any of the authors. 
PASI 75, PASI 90, and PASI 100 endpoints $(\geq 75, \geq 90$, and $100 \%$ improvement in PASI score, respectively) were analyzed at weeks 2,4 , 8 , and 12 , and missing values were handled using nonresponder imputation (NRI) in all studies, with the exception of four studies (CIMPACT [11], CIMPASI-1 [12], CIMPASI-2 [12], CLARITY [13]) that reported endpoints based on multiple imputation (MI). DLQI $(0,1)$ status, where $(0,1)$ indicates no effect/no impact on patient's life, was assessed at week 12, and missing values were handled using NRI in all studies, except for five studies (CIMPASI-1 [12], CIMPASI-2 [12], CLARITY [13], CLEAR [14], ERASURE [15]) that used last observation carried forward and one study (FIXTURE [15]) that did not mention how missing values were treated. When required data were imputed differently (e.g., MI vs. NRI) or analyzed (mixed model for repeated measures vs. analysis of covariance) differently, they were included in the data analysis based on the assumption that the impact of the chosen imputation/analytical method was negligible for treatment effects.

\section{Systematic Literature Review}

Efficacy data on PASI response rates (PASI 75/90/100) at weeks $2,4,8$, and 12 and DLQI $(0,1)$ response rates at week 12 were obtained from a systematic literature review of the OvidSP platform for literature published since 1 January 1990. The last update search was performed on 12 December 2018. The search parameters were designed to identify publications that reported data from phase 3 RCTs of biologics approved for the treatment of moderate-to-severe psoriasis. Studies included in the NMA are listed in ESM Table 1 [11-42]. The Cochrane Handbook for Systematic Reviews of Interventions guidance was followed [43].

\section{Outcome Measures Extracted}

We report the relative effects versus placebo for all biologics included in this study, except where data were unavailable. PASI 75/90/100 response data were unavailable at week 2 for risankizumab and tildrakizumab; PASI 100 response data were unavailable at weeks $2,4,8$, and 12 for certolizumab pegol and infliximab; and DLQI $(0,1)$ response data were unavailable at week 12 for guselkumab, infliximab, and risankizumab.

BNMA used fixed-treatment effect and randombaseline effect, normal independent models [44, 45]. Convergence for all models was assessed using trace plots as modified by Brooks and Gelman [46]. Model fit was assessed using the deviance information criterion, and residual deviance (technical model details are given in the ESM). fNMA were conducted as sensitivity analyses to test the robustness of the findings. BNMA were performed in JAGS via R using the R2JAGS package, and fNMA analysis was run using $\mathrm{R}$ version $3.4 .2 \mathrm{R}$ package with netmeta [47]. BNMA and fNMA included data from all biologic doses obtained during the systematic literature review (see ESM).

\section{RESULTS}

Based on the BNMA analysis, IL-17 antagonists showed the most rapid treatment effects, with ixekizumab and brodalumab being similar for rapid skin and quality of life responses (Figs. 1, 2, 3; Tables 1, 2).

Ixekizumab and brodalumab showed more rapid treatment effects on PASI 75 response rates at weeks 2,4 , and 8 compared with all other biologics included in the analysis (Figs. 1, 2; Table 1). At week 12, ixekizumab and risankizumab had the most rapid treatment effects; the distribution for ixekizumab overlapped with risankizumab, and the distribution for risankizumab overlapped with brodalumab, secukinumab, infliximab, and guselkumab (Figs. 1, 2; Table 1).

Similarly, ixekizumab and brodalumab showed more rapid treatment effects on PASI 90 response rates at weeks $2,4,8$, and 12 than did all of the other biologics included in the analysis (Figs. 1, 2; Table 1). Ixekizumab and brodalumab had the most rapid treatment effects at week 2 , brodalumab had the most rapid treatment effects at week 4, and ixekizumab and brodalumab had the most rapid treatment effects at weeks 8 and 12 where distributions overlapped (Figs. 1, 2; Table 1). Ixekizumab and brodalumab had no overlap but were followed at week 4 by infliximab and secukinumab and at 
PASI 75
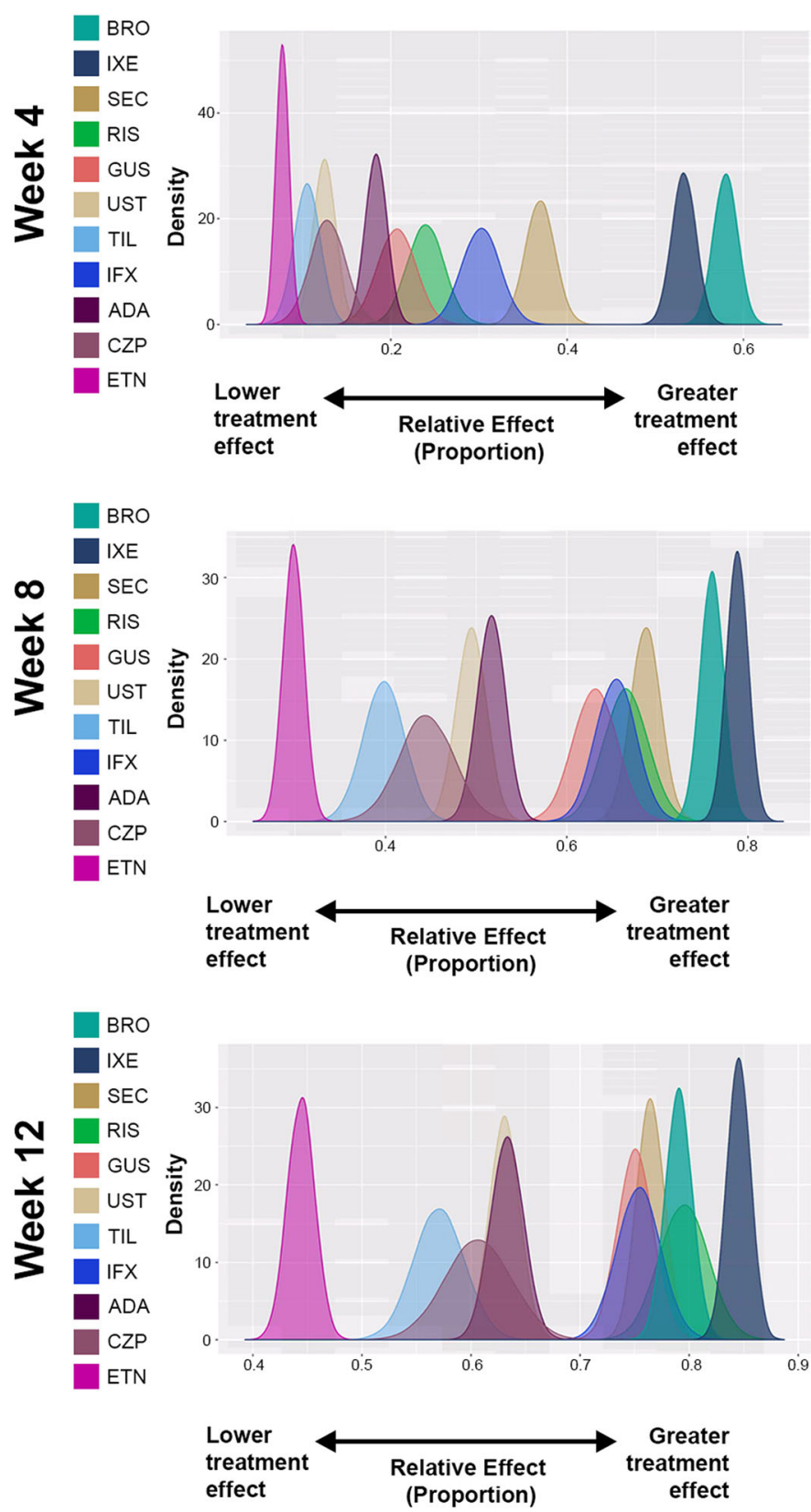

PASI 90
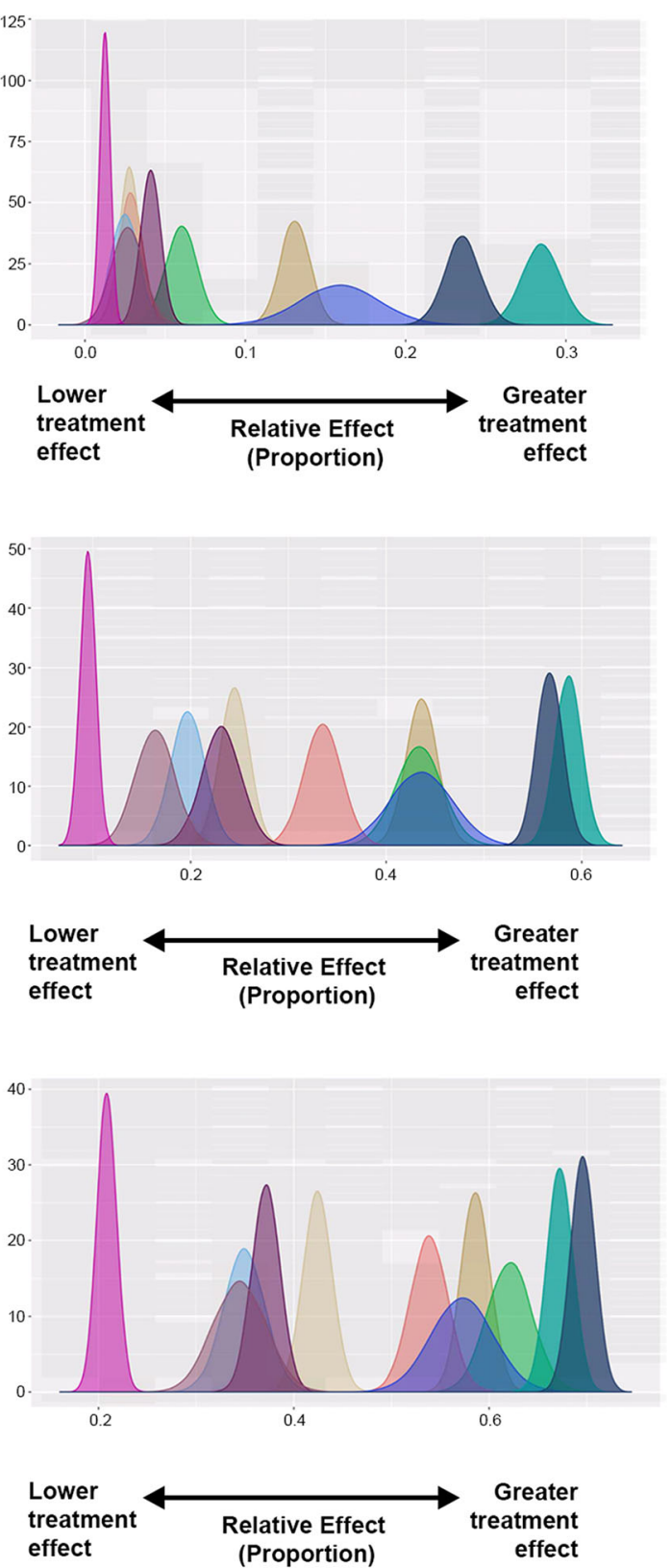

Fig. 1 Treatment effects on Psoriasis Area and Severity Index $(P A S I) 75$ and PASI 90 response rates $(\geq 75$ and $\geq 90 \%$ improvement in PASI, respectively) at weeks 4,8 , and 12 based on Bayesian Network Meta-Analysis (BNMA). Data are presented as the posterior mean

week 8 by secukinumab, infliximab, and risankizumab, and distributions did overlap for those treatments. At week 12, distributions for density relative to placebo. On-label doses are represented. $A D A$ Adalimumab, $B R O$ brodalumab, $C Z P$ certolizumab pegol, ETN etanercept, GUS guselkumab, IFX infliximab, $I X E$ ixekizumab, RIS risankizumab, SEC secukinumab, TIL tildrakizumab, UST ustekinumab

ixekizumab and brodalumab overlapped, and the distribution for brodalumab overlapped with risankizumab, which in turn overlapped 
PASI 75
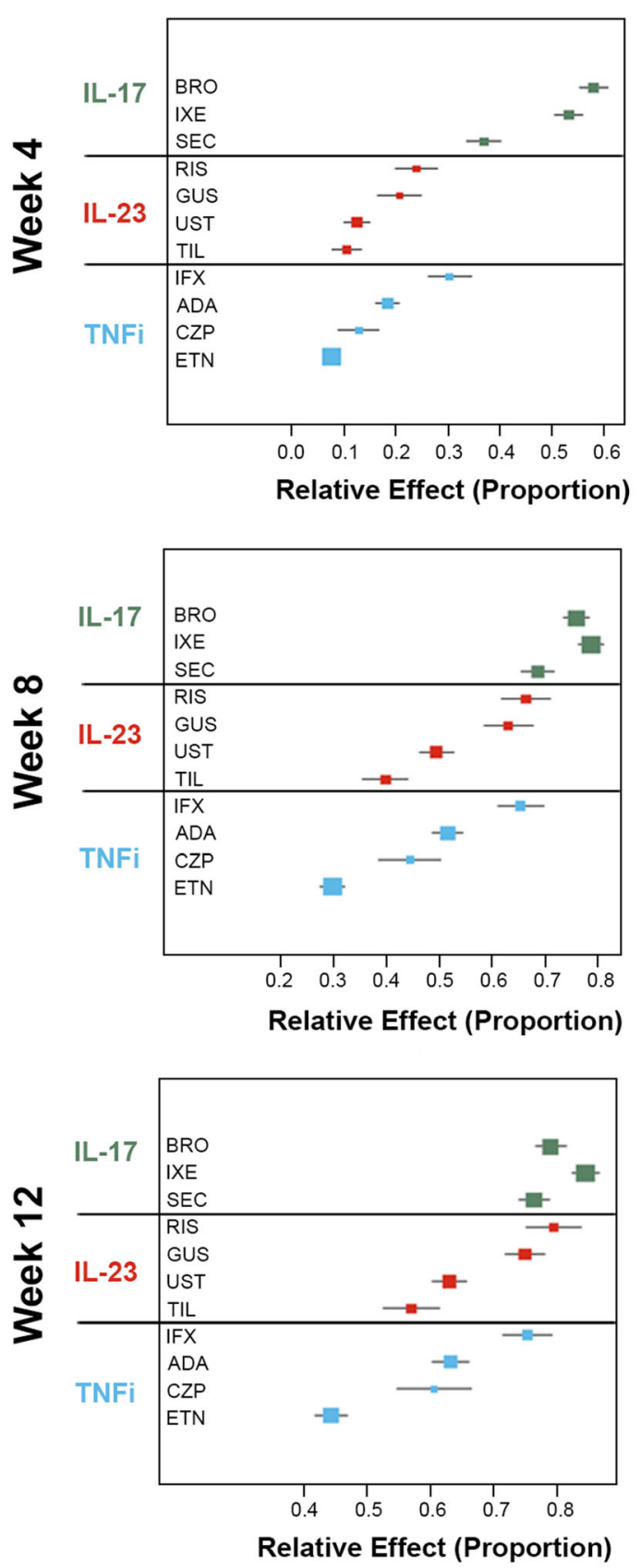

Fig. 2 Treatment effects on PASI 75 and PASI 90 response rates at weeks 4,8 , and 12 based on BNMA. Data are presented as the posterior mean and $95 \%$ credible interval relative to placebo. Boxes indicate sample size.

with secukinumab and infliximab (Figs. 1, 2; Table 1).
PASI 90
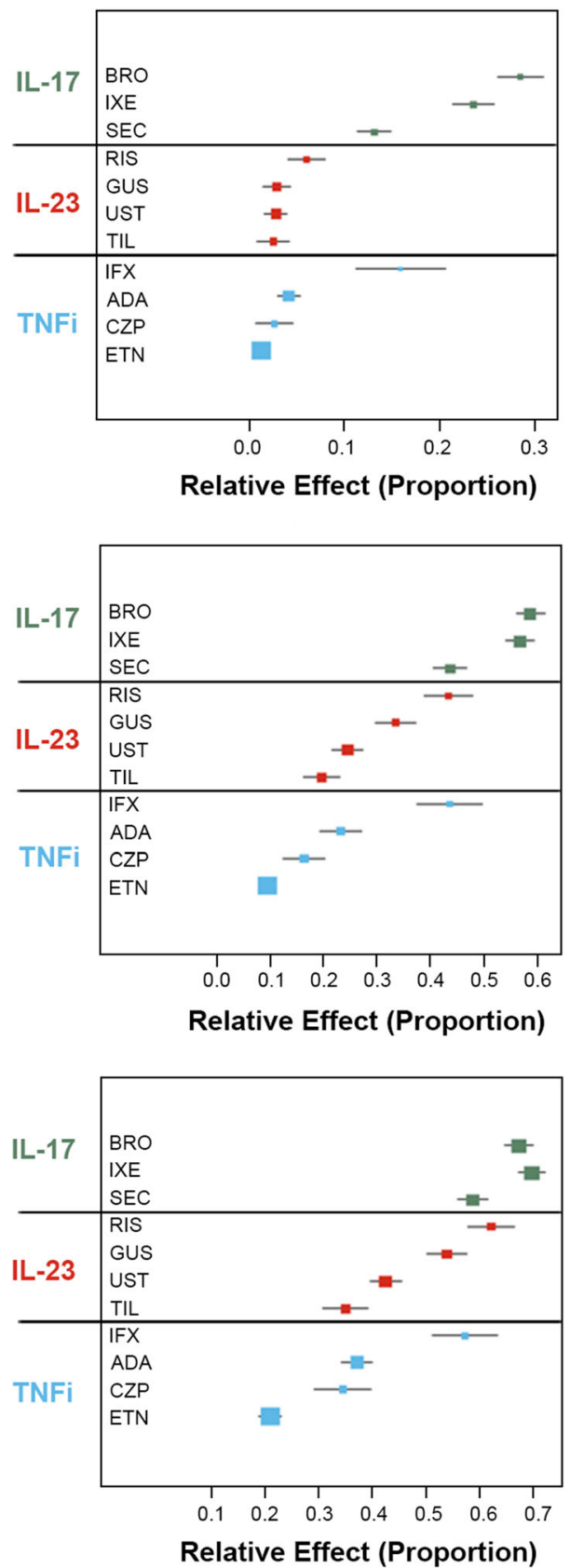

Ustekinumab is an interleukin (IL)-12/-23 inhibitor. Onlabel doses are represented. TNFi Tumor necrosis factor inhibitor

Ixekizumab and brodalumab showed the most rapid treatment effects for PASI 100 at 


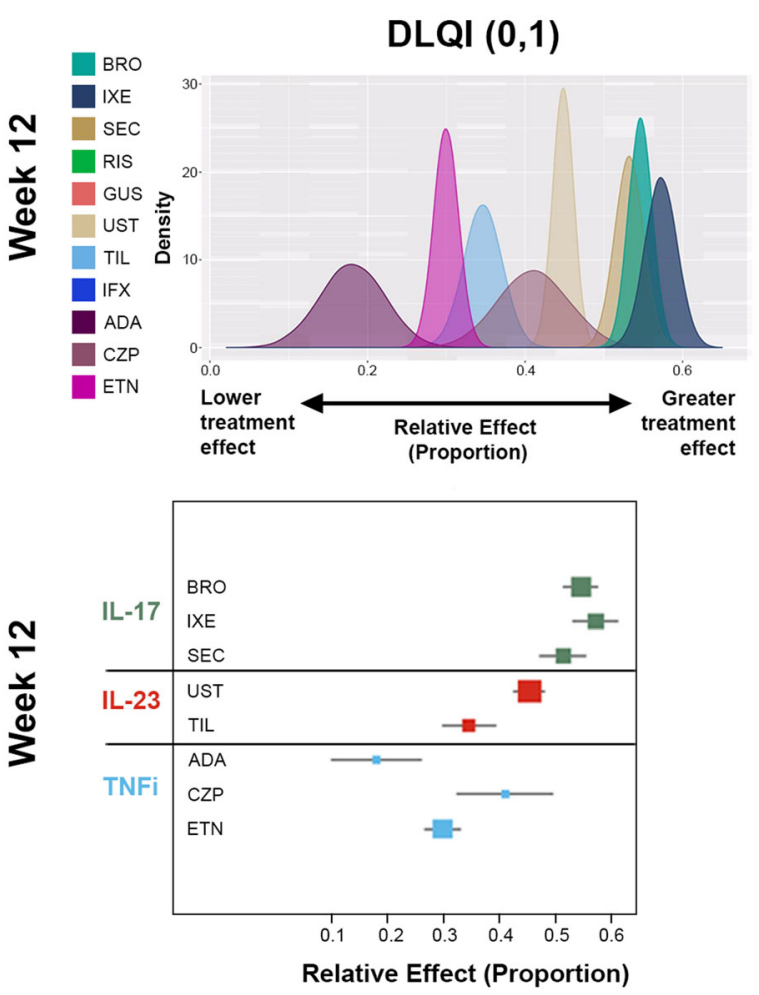

Fig. 3 Treatment effects on the Dermatology Life Quality Index (DLQI) $(0,1)$ response rates at week 12 based on BNMA. Score $(0,1)$ indicates no effect on patient. Data are presented as the posterior mean density relative to placebo. Guselkumab and infliximab data were not available at week 12. Ustekinumab is an IL-12/-23 inhibitor. On-label doses are represented

weeks 4 and 12, and brodalumab showed the most rapid treatment effects at week 8 (Table 1; ESM Figs. 1, 2).

Average (i.e., posterior mean) relative treatment effect was greatest for ixekizumab, brodalumab, and secukinumab on the DLQI $(0,1)$ response rates at week 12 , where distributions overlapped for these three treatments (Fig. 3; Table 2).

Results from fNMA were consistent with those from BNMA, with similar treatment rankings for PASI 75/90/100 at weeks 2, 4, 8, and 12 and for DLQI $(0,1)$ at week 12 . PASI 90 at week 12 rankings are presented (Table 3 ). Ixekizumab and brodalumab were ranked highest compared with the other biologics included in the fNMA analysis. Network diagrams are presented for PASI 90 at week 12 (Fig. 4). In Fig. 4, lines represent direct comparisons using RCTs, and numbers represent the number of RCTs included in each comparison.

\section{DISCUSSION}

In this comprehensive NMA of phase 3 RCTs, ixekizumab and brodalumab provided the most rapid and highest clinical response of PASI 75, PASI 90, or PASI 100 as early as week 2 compared to other biologic treatments (secukinumab, ustekinumab, guselkumab, adalimumab, and etanercept). DLQI $(0,1)$ response rate distributions at week 12 overlapped for ixekizumab, brodalumab, and secukinumab. BNMA and fNMA results showed similar relative effect estimates with comparable treatment rankings. These findings align with previously published reports of rapid clinical improvement for patients with moderate-tosevere psoriasis treated with ixekizumab or brodalumab [48-50].

Rapid improvements in skin and the ability to feel better quickly are important treatment attributes of a psoriasis therapy. These are important patient preferences for treatments and are ranked among the highest desired priorities in multiple reports $[2,4,9,10,51,52]$. However, rapid effect is also tied to longer-term outcomes, including skin improvement, quality of life, and reduction in itch [50,53-55], though it must be noted that an association between rapid effect and long-term outcomes was not assessed in this analysis. It is also important to note that each patient has different treatment expectations $[51,56]$ and that the alignment of individual patient needs with physician goals may improve adherence and satisfaction with therapy [56].

Several limitations to this study should be considered. NMA differs from a traditional meta-analysis in that it is not an analysis of only head-to-head studies of the same intervention with the same comparator. NMA relies on a network of evidence from RCTs where relevant treatments are connected by trials, and this provides a combination of direct and indirect comparisons for analysis of the comparative effects of many interventions [57]. RCTs are 


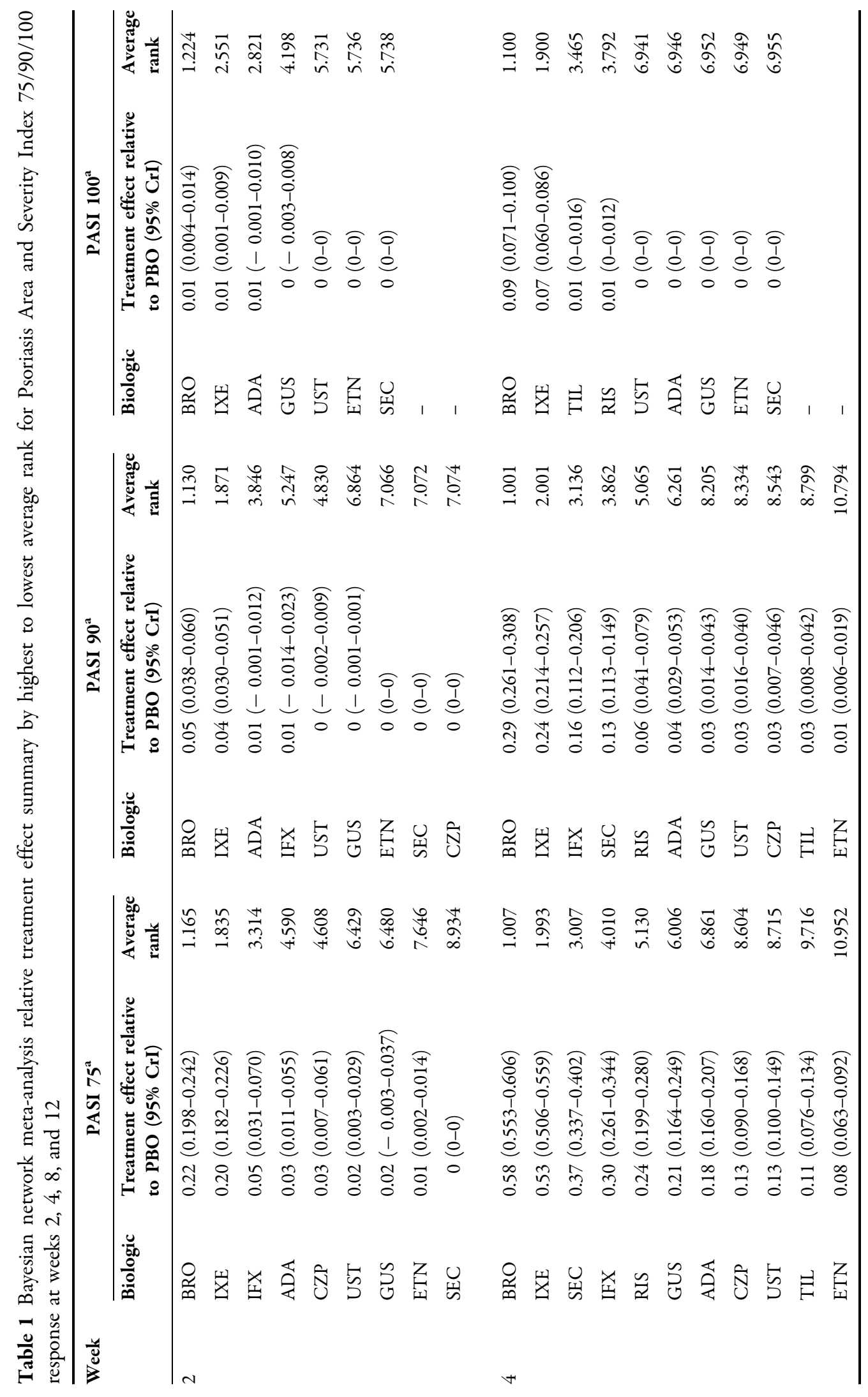




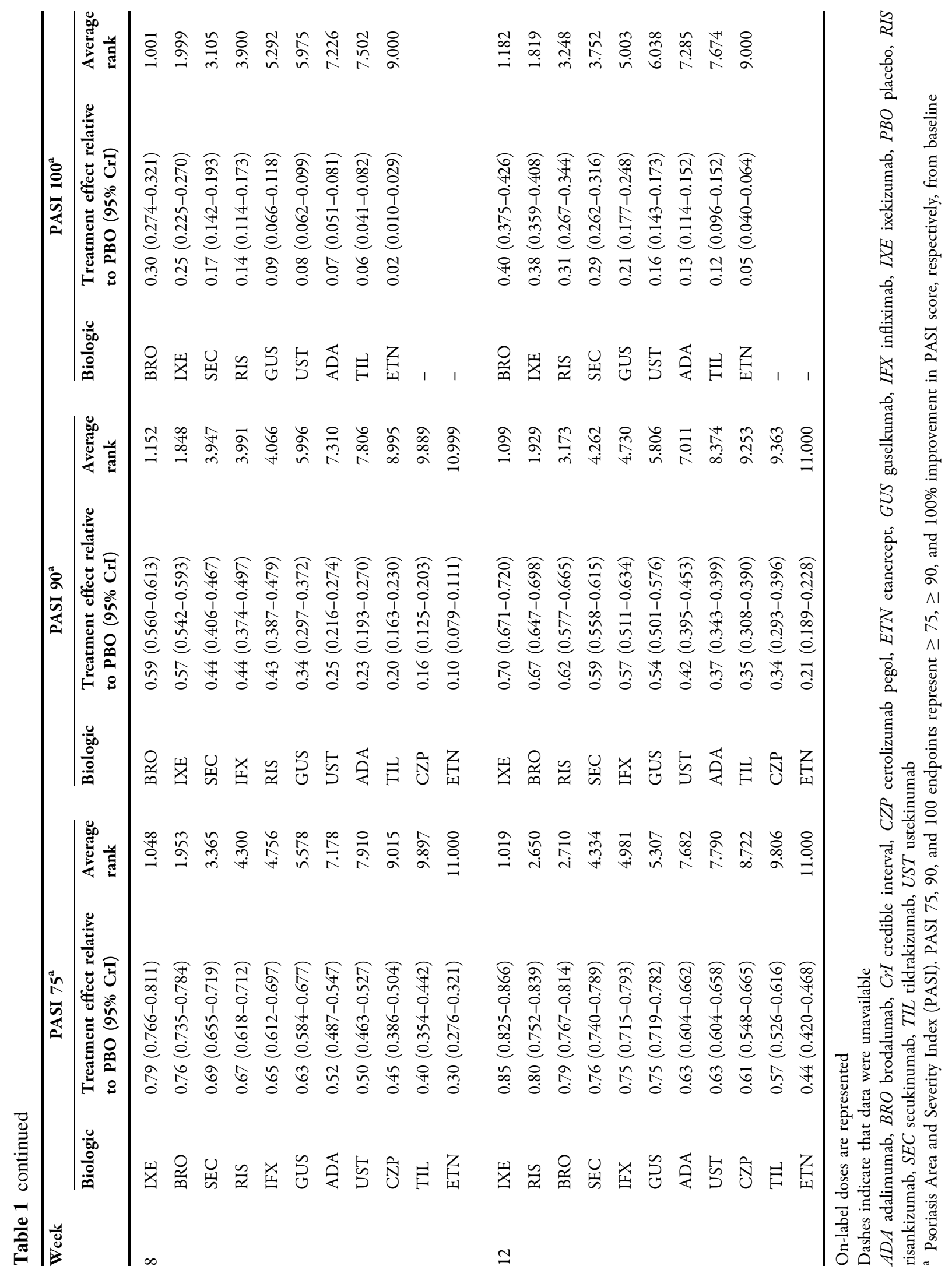


Table 2 Bayesian network meta-analysis relative treatment effect summary by highest to lowest average rank for the Dermatology Life Quality Index $(0,1)$ response at week 12

\begin{tabular}{lll}
\hline \multicolumn{3}{c}{ DLQI $(\mathbf{0 , 1})$ response at week 12 } \\
\hline Biologic & $\begin{array}{l}\text { Treatment effect relative to PBO } \\
(\mathbf{9 5 \%} \text { CrI })\end{array}$ & $\begin{array}{l}\text { Average } \\
\text { rank }\end{array}$ \\
\hline IXE & $0.57(0.533-0.612)$ & 1.207 \\
BRO & $0.55(0.517-0.576)$ & 2.120 \\
SEC & $0.53(0.497-0.567)$ & 2.680 \\
UST & $0.45(0.423-0.474)$ & 4.209 \\
CZP & $0.41(0.324-0.497)$ & 4.892 \\
TIL & $0.35(0.300-0.393)$ & 5.942 \\
ETN & $0.30(0.269-0.330)$ & 6.953 \\
ADA & $0.18(0.101-0.260)$ & 7.997 \\
\hline
\end{tabular}

On-label doses are represented

DLQI $(0,1)$ Dermatology Life Quality Index $(0,1)$

considered to be the gold standard for treatment comparisons and provide valuable clinical data, and the studies included in the analyses are assumed to be generally similar and consistent; however, heterogeneity still may exist. There may be clinical differences (participants, populations [naïve versus experienced], duration of follow-up, and mode of administration) and methodological differences (study design, approaches to analysis, and imputation methods) that may not be aligned due to the availability of or clarity in the published data. For example, an insufficient number of RCTs included in this analysis had DLQI $(0,1)$ response rates available at time points earlier than week 12; the threshold for NMA inclusion was not met and, thus, earlier quality of life response was not evaluated. This may contribute to selection and reporting bias. The way endpoints were imputed was clear in the majority of studies included in the analysis; however, the imputation method used for DLQI $(0,1)$ missing values was not mentioned in one study (FIXTURE [15]). Another important caveat is that quality of life was limited in this report by what the DLQI tool could capture in
Table 3 Frequentist network meta-analysis treatment rankings for Psoriasis Area and Severity Index 90 response rates at week 12

\begin{tabular}{lll}
\hline Biologic & $\begin{array}{l}\text { Treatment effect relative to } \\
\text { PBO }(95 \% \text { CI })\end{array}$ & $\begin{array}{l}\text { Rank } \\
(\boldsymbol{P} \text { score })\end{array}$ \\
\hline IXE & $0.70(0.671-0.720)$ & 0.995 \\
BRO & $0.67(0.647-0.698)$ & 0.951 \\
RIS & $0.62(0.577-0.665)$ & 0.865 \\
SEC & $0.59(0.557-0.614)$ & 0.780 \\
IFX & $0.57(0.511-0.633)$ & 0.756 \\
GUS & $0.54(0.502-0.577)$ & 0.695 \\
UST & $0.42(0.395-0.453)$ & 0.526 \\
ADA & $0.37(0.344-0.400)$ & 0.359 \\
TIL & $0.35(0.308-0.390)$ & 0.287 \\
CZP & $0.34(0.284-0.391)$ & 0.257 \\
ETN & $0.21(0.188-0.227)$ & 0.105 \\
\hline
\end{tabular}

On-label doses are represented

the narrow RCT population. Our focus was limited to the first 12 weeks of treatment, and as such, long-term quality of life impacts of psoriasis and costs associated with disease management were not examined. Safety and patient-reported outcomes data, including those related to quality of life, were not examined in this report. The NMA results presented here are not direct comparisons and should be interpreted with caution if used to inform future treatment choices. Finally, results cannot be generalized by class because not all members of the IL-17 superfamily of cytokines were shown to be rapid in this analysis and there was some overlap between these and members of different classes, such as IL-23.

\section{CONCLUSIONS}

Overall, this NMA demonstrates that ixekizumab and brodalumab provide the most rapid skin clearance and quality of life improvement within 12 weeks compared with other leading biologic treatments for patients with moderate- 


\section{PASI 90 Network Diagram at Week 12}

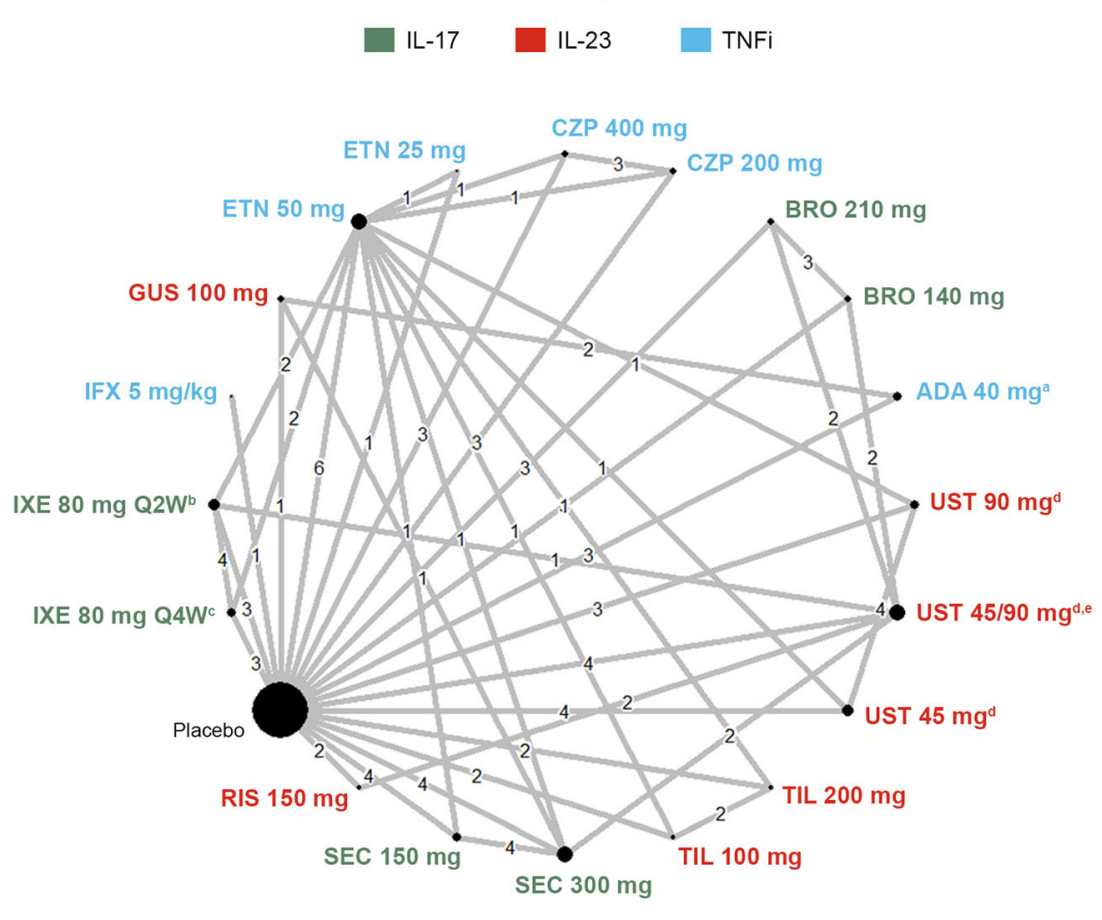

a $80 \mathrm{mg}$ loading dose on Day 1, then $40 \mathrm{mg}$ on Day 8 and $40 \mathrm{mg}$ Q2W thereafter

b $160 \mathrm{mg}$ loading dose on Day 1 and then $80 \mathrm{mg} \mathrm{Q2W}$ thereafter

c $160 \mathrm{mg}$ loading dose on Day 1 and then $80 \mathrm{mg} \mathrm{Q} 4 \mathrm{~W}$ thereafter

d UST is an IL-12/-23 inhibitor

e $45 \mathrm{mg}$ for patients $\leq 100 \mathrm{~kg}$ and $90 \mathrm{mg}$ for patients $>100 \mathrm{~kg}$

Fig. 4 PASI 90 network diagram at week 12. A total of 33 studies and 20 treatments are included. On- and off-label doses are represented. Lines represent direct comparisons using randomized, controlled trials (RCTs); numbers

to-severe psoriasis, including secukinumab, an IL-17 antagonist, and biologics that inhibit the IL-12/-23, IL-23, or TNF pathways.

\section{ACKNOWLEDGEMENTS}

Funding. This study and the journal's Rapid Service Fee were sponsored by Eli Lilly and Company. Richard B. Warren is supported by the Manchester NIHR Biomedical Research Centre. All authors had full access to all of the data in this study and take complete responsibility for the integrity of the data and accuracy of the data analysis. represent the number of RCTs included in each comparison; network diagrams are the same for both BNMA and frequentist network meta-analysis. $Q 2 W$ Every 2 weeks, $Q 4 W$ every 4 weeks

Medical Writing Support. Medical writing services were provided by Melody Pupols, PhD, of Syneos Health, and support for this assistance was funded by Eli Lilly and Company.

Authorship. All named authors meet the International Committee of Medical Journal Editors (ICMJE) criteria for authorship for this article, take responsibility for the integrity of the work as a whole, and have given their approval for this version to be published.

Disclosures. Richard B. Warren has been a consultant and/or speaker for: AbbVie, Almirall, Amgen, Boehringer Ingelheim, Bristol-Myers Squibb, Celgene, Eli Lilly and Company, GlaxoSmithKline, Janssen, Leo Pharma, 
Novartis, Sanofi Genzyme, and UCB Pharma. Alexander Egeberg has been an advisory board member, and/or consultant, and/or investigator, and/or speaker for: Almirall, Bristol-Myers Squibb, Dermavant, Eli Lilly and Company, Galderma, Janssen, Leo Pharma, Novartis, Pfizer, and Samsung Bioepis. Kyoungah See is an employee and shareholder of Eli Lilly and Company. Russel Burge is an employee and shareholder of Eli Lilly and Company. Ying Zhang is an employee and shareholder of Eli Lilly and Company. Alan Brnabic is an employee and shareholder of Eli Lilly and Company. Gaia Gallo is an employee and shareholder of Eli Lilly and Company. Alyssa Garrelts is an employee and shareholder of Eli Lilly and Company.

Compliance with Ethics Guidelines. This article is based on previously conducted studies and does not contain any studies with human participants or animals performed by any of the authors.

Data Availability. Portions of this work were presented at the American Academy of Dermatology Annual Meeting in Washington, DC; 1-5 March 2019. The datasets generated during and/or analyzed during the current study are not publicly available due to the systematic literature review/network meta-analysis (SLR/NMA) being completed before registration with a database such as The International Prospective Register of Systematic Reviews (PROSPERO) was a requirement. Any future updates to this SLR/NMA will be registered in PROSPERO. The datasets generated during and/ or analyzed during the current study are available from the corresponding author on reasonable request.

Open Access. This article is distributed under the terms of the Creative Commons Attribution-NonCommercial 4.0 International License (http://creativecommons.org/licenses/ by-nc/4.0/), which permits any noncommercial use, distribution, and reproduction in any medium, provided you give appropriate credit to the original author(s) and the source, provide a link to the Creative Commons license, and indicate if changes were made.

\section{REFERENCES}

1. Vanderpuye-Orgle J, Zhao Y, Lu J, et al. Evaluating the economic burden of psoriasis in the United States. J Am Acad Dermatol. 2015;72(961-7):e5.

2. World Health Organization. Global report on psoriasis. Geneva: World Health Organization; 2016. http://apps.who.int/iris/bitstream/handle/10665/ 204417/9789241565189_eng.pdf.psoriasis;jsession id=E453601C761C054A2 354BED72A2B5FCA?sequ ence $=1$. Accessed June 2019 .

3. Warren RB, Brnabic A, Saure D, et al. Matchingadjusted indirect comparison of efficacy in patients with moderate-to-severe plaque psoriasis treated with ixekizumab vs. secukinumab. Br J Dermatol. 2017;178:1064-71.

4. Papp KA, Lebwohl MG. Onset of action of biologics in patients with moderate-to-severe psoriasis. J Drugs Dermatol. 2017;17:247-50.

5. Ogawa E, Sato Y, Minagawa A, Okuyama R. Pathogenesis of psoriasis and development of treatment. J Dermatol. 2018;45:264-72.

6. Liu L, Lu J, Allan BW, et al. Generation and characterization of ixekizumab, a humanized monoclonal antibody that neutralizes interleukin-17A. J Inflamm Res. 2016;9:39-50.

7. Uhlenhake EE, Kurkowski D, Feldman SR. Conversations on psoriasis-what patients want and what physicians can provide: a qualitative look at patient and physician expectations. J Dermatolog Treat. 2010;21:6-12.

8. Blome C, Gosau R, Radtke MA, et al. Patient-relevant treatment goals in psoriasis. Arch Dermatol Res. 2016;308:69-78.

9. Korman NJ, Zhao Y, Lu J, Tran MH. Psoriasis disease severity affects patient satisfaction with treatment. Dermatol Online J. 2015;21(7).

10. Seston EM, Ashcroft DM, Griffiths CE. Balancing the benefits and risks of drug treatment: a statedpreference, discrete choice experiment with patients with psoriasis. Arch Dermatol. 2007;143:1175-9.

11. Lebwohl M, Blauvelt A, Paul C, et al. Certolizumab pegol for the treatment of chronic plaque psoriasis: results through 48 weeks of a phase 3 , multicenter, randomized, double-blind, etanercept- and 
placebo-controlled study (CIMPACT). J Am Acad Dermatol. 2018;79(266-76):e5.

12. Gottlieb AB, Blauvelt A, Thaçi D, et al. Certolizumab pegol for the treatment of chronic plaque psoriasis: results through 48 weeks from 2 phase 3, multicenter, randomized, double-blinded, placebo-controlled studies (CIMPASI-1 and CIMPASI-2). J Am Acad Dermatol. 2018;79(302-14):e6.

13. Bagel J, Nia J, Hashim PW, et al. Secukinumab is superior to ustekinumab in clearing skin in patients with moderate to severe plaque psoriasis (16-week CLARITY results). Dermatol Ther (Heidelb). 2018;8:571-9.

14. Thaçi D, Blauvelt A, Reich K, et al. Secukinumab is superior to ustekinumab in clearing skin of subjects with moderate to severe plaque psoriasis: CLEAR, a randomized controlled trial. J Am Acad Dermatol. 2015;73:400-9.

15. Langley RG, Elewski BE, Lebwohl M, et al. Secukinumab in plaque psoriasis-results of two phase 3 trials. N Engl J Med. 2014;371:326-38.

16. Saurat JH, Stingl G, Dubertret L, et al. Efficacy and safety results from the randomized controlled comparative study of adalimumab vs. methotrexate vs. placebo in patients with psoriasis (CHAMPION). Br J Dermatol. 2008;158:558-66.

17. Menter A, Tyring SK, Gordon K, et al. Adalimumab therapy for moderate to severe psoriasis: a randomized, controlled phase III trial. J Am Acad Dermatol. 2008;58:106-15.

18. Blauvelt A, Papp KA, Griffiths CE, et al. Efficacy and safety of guselkumab, an anti-interleukin-23 monoclonal antibody, compared with adalimumab for the continuous treatment of patients with moderate to severe psoriasis: results from the phase III, double-blinded, placebo- and active comparatorcontrolled VOYAGE 1 trial. J Am Acad Dermatol. 2017;76:405-17.

19. Reich K, Armstrong AW, Foley P, et al. Efficacy and safety of guselkumab, an anti-interleukin-23 monoclonal antibody, compared with adalimumab for the treatment of patients with moderate to severe psoriasis with randomized withdrawal and retreatment: results from the phase III, double-blind, placebo- and active comparator-controlled VOYAGE 2 trial. J Am Acad Dermatol. 2017;76:418-31.

20. Cai L, Gu J, Zheng J, et al. Efficacy and safety of adalimumab in Chinese patients with moderate-tosevere plaque psoriasis: results from a phase 3 , randomized, placebo-controlled, double-blind study. J Eur Acad Dermatol Venereol. 2017;31:89-95.
21. Papp KA, Reich K, Paul C, et al. A prospective phase III, randomized, double-blind, placebo-controlled study of brodalumab in patients with moderate-tosevere plaque psoriasis. $\mathrm{Br} \mathrm{J}$ Dermatol. 2016;175:273-86.

22. Lebwohl M, Strober B, Menter A, et al. Phase 3 studies comparing brodalumab with ustekinumab in psoriasis. N Engl J Med. 2015;373:1318-28.

23. Papp KA, Tyring S, Lahfa M, et al. A global phase III randomized controlled trial of etanercept in psoriasis: safety, efficacy, and effect of dose reduction. $\mathrm{Br}$ J Dermatol. 2005;152:1304-12.

24. Griffiths CE, Strober BE, van de Kerkhof P, et al. Comparison of ustekinumab and etanercept for moderate-to-severe psoriasis. $\mathrm{N}$ Engl $\mathrm{J}$ Med. 2010;362:118-28.

25. Griffiths CE, Reich K, Lebwohl M, et al. Comparison of ixekizumab with etanercept or placebo in moderate-to-severe psoriasis (UNCOVER-2 and UNCOVER-3): results from two phase 3 randomised trials. Lancet. 2015;386:541-51.

26. Gordon KB, Blauvelt A, Papp KA, et al. Phase 3 trials of ixekizumab in moderate-to-severe plaque psoriasis. N Engl J Med. 2016;375:345-56.

27. Reich K, Papp KA, Blauvelt A, et al. Tildrakizumab versus placebo or etanercept for chronic plaque psoriasis (reSURFACE 1 and reSURFACE 2): results from two randomised controlled, phase 3 trials. Lancet. 2017;390:276-88.

28. Johnson and Johnson. New Phase 3 data demonstrate superiority of TREMFYA ${ }^{\circledR}$ (guselkumab) vs Cosentyx ${ }^{\circledR}$ (secukinumab) in delivering PASI 90 responses in the treatment of moderate to severe plaque psoriasis at week 48 [Internet]. New Brunswick: Johnson and Johnson; 2018. https://www.jnj. $\mathrm{com} /$ new-phase-3-data-demonstrate-superiority-oftremfya-guselkumab-vs-cosentyx-secukinumab-indelivering-pasi-90-responses-in-the-treatment-ofmoderate-to-severe-plaque-psoriasis-at-week- 48 . Accessed 25 Jun 2019.

29. Reich K, Armstrong A, Blauvelt A, et al. Guselkumab demonstrates superior long-term responses compared with secukinumab in the treatment of moderate to severe plaque psoriasis: Results from the ECLIPSE trial. Poster presented at the 6th Congress of the Skin Inflammation \& Psoriasis International Network, Paris, France, 25-27 April 2019.

30. Langley R, Blauvelt A, Armstrong A, et al. Guselkumab demonstrates superior long-term responses to secukinumab at week 48 in the treatment of moderate to severe psoriasis: results from the ECLIPSE trial. Poster presented at the 3rd Inflammatory Skin Disease Summit, Vienna, Austria, 12-15 December 2019. 
31. Reich K, Nestle FO, Papp K, et al. Infliximab induction and maintenance therapy for moderateto-severe psoriasis: a phase III, multicentre, doubleblind trial. Lancet. 2005;366:1367-74.

32. Menter A, Feldman SR, Weinstein GD, et al. A randomized comparison of continuous vs. intermittent infliximab maintenance regimens over 1 year in the treatment of moderate-to-severe plaque psoriasis. J Am Acad Dermatol. 2007;56:31.e1-15.

33. Reich K, Pinter A, Lacour JP, et al. Comparison of ixekizumab with ustekinumab in moderate-to-severe psoriasis: 24-week results from IXORA-S, a phase III study. Br J Dermatol. 2017;177:1014-23.

34. Paul C, Griffiths CEM, van de Kerkhof PCM, et al. Ixekizumab provides superior efficacy compared with ustekinumab over 52 weeks of treatment: results from IXORA-S, a phase 3 study. J Am Acad Dermatol. 2019;80(70-9):e3.

35. Langley RG, Papp K, Gooderham M, et al. Efficacy and safety of continuous every-2-week dosing of ixekizumab over 52 weeks in patients with moderate-to-severe plaque psoriasis in a randomized phase III trial (IXORA-P). $\mathrm{Br} \mathrm{J}$ Dermatol. 2018;178:1315-23.

36. Gordon KB, Strober B, Lebwohl M, et al. Efficacy and safety of risankizumab in moderate-to-severe plaque psoriasis (UltIMMa-1 and UltIMMa-2): results from two double-blind, randomised, placebo-controlled and ustekinumab-controlled phase 3 trials. Lancet. 2018;392:650-61.

37. Blauvelt A, Prinz JC, Gottlieb AB, et al. Secukinumab administration by pre-filled syringe: efficacy, safety and usability results from a randomized controlled trial in psoriasis (FEATURE). Br J Dermatol. 2015;172:484-93.

38. Paul C, Lacour JP, Tedremets L, et al. Efficacy, safety and usability of secukinumab administration by autoinjector/pen in psoriasis: a randomized, controlled trial (JUNCTURE). J Eur Acad Dermatol Venereol. 2015;29:1082-90.

39. Tsai TF, Ho JC, Song M, et al. Efficacy and safety of ustekinumab for the treatment of moderate-to-severe psoriasis: a phase III, randomized, placebocontrolled trial in Taiwanese and Korean patients (PEARL). J Dermatol Sci. 2011;63:154-63.

40. Leonardi CL, Kimball AB, Papp KA, et al. Efficacy and safety of ustekinumab, a human interleukin$12 / 23$ monoclonal antibody, in patients with psoriasis: 76-week results from a randomised, doubleblind, placebo-controlled trial (PHOENIX 1). Lancet. $2008 ; 371: 1665-74$.
41. Papp KA, Langley RG, Lebwohl M, et al. Efficacy and safety of ustekinumab, a human interleukin$12 / 23$ monoclonal antibody, in patients with psoriasis: 52-week results from a randomised, doubleblind, placebo-controlled trial (PHOENIX 2). Lancet. $2008 ; 371: 1675-84$.

42. Igarashi A, Kato T, Kato M, Song M, Nakagawa $H$. Efficacy and safety of ustekinumab in Japanese patients with moderate-to-severe plaque-type psoriasis: long-term results from a phase $2 / 3$ clinical trial. J Dermatol. 2012;39:242-52.

43. Cochrane Training. Cochrane handbook for systematic reviews of interventions. Cochrane; 2017. http://training.cochrane.org/handbook. Accessed 25 Jun 2019

44. Dias S, Welton NJ, Sutton AJ, Caldwell DM, Lu G, Ades AE. Evidence synthesis for decision making 4: inconsistency in networks of evidence based on randomized controlled trials. Med Decis Making. 2013;33:641-56.

45. Dias S, Welton NJ, Sutton AJ, Ades AE. NICE DSU Technical Support Document 2: A generalised linear modelling framework for pairwise and network meta-analysis of randomised controlled trials. 2011, last updated 2016. http://www.nicedsu.org.uk. Accessed 8 Oct 2019.

46. Brooks SP, Gelman A. General methods for monitoring convergence of iterative simulations. J Comput Graph Stat. 1998;7:434-55.

47. Rücker G. Network meta-analysis, electrical networks and graph theory. Res Synth Methods. 2012;3:312-24.

48. Blauvelt A, Papp KA, Lebwohl MG, et al. Rapid onset of action in patients with moderate-to-severe psoriasis treated with brodalumab: a pooled analysis of data from two phase 3 randomized clinical trials (AMAGINE-2 and AMAGINE-3). J Am Acad Dermatol. 2017;77:372-4.

49. Leonardi C. Rapid onset of efficacy in patients with psoriasis treated with ixekizumab: A pooled analysis of data from two phase 3 randomized clinical trials (UNCOVER-2 and UNCOVER-3). J Am Acad Dermatol. 2016;74:AB70.

50. Pinter A, Amato D, Burge R, et al. Ixekizumab treatment results in more rapid clinical improvements in patients with moderate-to-severe psoriasis compared to ustekinumab: results from the IXORA$\mathrm{S}$ trial. Poster presented at the American Academy of Dermatology Annual Meeting, Washington DC, 1-5 March 2019. 
51. Torbica A, Fattore G, Ayala F. Eliciting preferences to inform patient-centred policies: the case of psoriasis. Pharmacoeconomics. 2014;32:209-23.

52. Paul C, Guenther L, Torii H, et al. Impact of ixekizumab on facial psoriasis and related quality of life measures in moderate-to-severe psoriasis patients: 12-week results from two phase III trials. J Eur Acad Dermatol Venereol. 2018;32:68-72.

53. Kimball AB, Gieler U, Linder D, Sampogna F, Warren $\mathrm{RB}$, Augustin M. Psoriasis: is the impairment to a patient's life cumulative? J Eur Acad Dermatol Venereol. 2010;24:989-1004.

54. Yosipovitch G, Reich A, Steinhoff M, et al. Impact of ixekizumab treatment on itch and Psoriasis Area and Severity Index in patients with moderate-tosevere plaque psoriasis: an integrated analysis of two phase III randomized studies. Dermatol Ther (Heidelb). 2018;8:621-37.
55. Augustin M, Gooderham M, Amato D, et al. Rapid clinical response predicts consistent long-term response in patients with moderate-to-severe psoriasis: ixekizumab versus ustekinumab. Poster presented at the American Academy of Dermatology Annual Meeting, Washington DC, 1-5 March 2009.

56. Strohal R, Prinz JC, Girolomoni G, Nast A. A patient-centred approach to biological treatment decision making for psoriasis: an expert consensus. J Eur Acad Dermatol Venereol. 2015;29:2390-8.

57. Hoaglin DC, Hawkins N, Jansen JP, et al. Conducting indirect-treatment-comparison and network-meta-analysis studies: report of the ISPOR Task Force on Indirect Treatment Comparisons Good Research Practices: part 2. Value Health. 2011;14:429-37. 